\title{
Phytochemicals Study, Antioxidant and Cytotoxicity Properties of Hydnophytum formicarum (Kepala beruk) Leaves against HepG2 and HeLa Cell Lines
}

\section{MOGESH SABABATHY ${ }^{1,2}$, MURNI NUR ISLAMIAH KASSIM ${ }^{1}$, AHMAD SHAMSUDIN AHMAD², HERMANSYAH AMIR ${ }^{3}$, DESY FITRYA SYAMSUMIR ${ }^{1}$ and YOSIE ANDRIANI ${ }^{\text {* }}$}

${ }^{1}$ Institute of Marine Biotechnology, Universiti Malaysia Terengganu, 21030 Kuala Nerus, Terengganu, Malaysia.

${ }^{2}$ Faculty of Science and Marine Environment, Universiti Malaysia Terengganu, 21030 Kuala Nerus,

Terengganu, Malaysia.

${ }^{3}$ Educational Chemistry Program, Faculty of Teacher Training and Education,

Bengkulu University, Bengkulu, Indonesia.

${ }^{*}$ Corresponding author E-mail: yosie.hs@umt.edu.my

http://dx.doi.org/10.13005/ojc/360310

(Received: May 01, 2020; Accepted: June 15, 2020)

\section{ABSTRACT}

\begin{abstract}
Study on phytochemistry, antioxidant and cytotoxicity properties of Hydnophytum formicarum leaves against HepG2 and HeLa cancer cell lines were described. The leaves were dried in a freeze dryer and successively extracted using hexane and methanol. Phytochemicals screening revealed the presence of several compounds including phenols/tannins, flavonoids, glycosides and steroids. Antioxidant property was examined using DPPH free radical scavenging assay. Methanol extract exhibited higher antioxidant activity $\left(\mathrm{IC}_{50}=0.4 \mathrm{mg} / \mathrm{mL}\right)$ compared to hexane extract $\left(\mathrm{IC}_{50}=2 \mathrm{mg} / \mathrm{mL}\right)$. However, the cytotoxicity result by MTT assay showed only methanol extract exhibited moderate cytotoxic activity against HeLa cell line $\left(\mathrm{IC}_{50}=25 \mathrm{mg} / \mathrm{mL}\right)$. Both extracts showed no cytotoxic activity against HepG2 cell line. This study suggests that $H$. formicarum leaves have potency as a new source of antioxidant and anticancer agents, especially for cervical cancer. However, further study to separate the bioactive compounds of the extract and by using different cell lines is required to discover the potential of $H$. formicarum leaves as antioxidant and anticancer agents.
\end{abstract}

Keywords: Hydnophytum formicarum (Kepala beruk), Antioxidant, Cytotoxicity, HepG2, HeLa.

\section{INTRODUCTION}

Traditional practices of using herbals plants to cure diseases since the past centuries could be one of the biggest contribution to the advancements and discoveries in the modern medicine field today.
Plants are still of a huge interest to many researches especially in the efforts of understanding the mechanisms and its phytochemical composition, for instance that would be a great help in discovering new drugs in order to suppress if not completely stop deadly disease like cancer. Cancer has been

This is an Open Access article licensed under a Creative Commons license: Attribution 4.0 International (CC- BY). Published by Oriental Scientific Publishing Company @ 2018

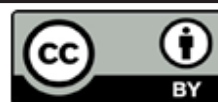


reported to be the leading cause of deaths in the world with an estimate of 9.6 million deaths in 2018 and is expected to reach over thirteen million in $2030^{1}$. According to Khan², more than $60 \%$ of currently used anti-cancer agents are derivatives of natural sources such as plants besides factors like easily available, inexpensive and less toxic, it is a reason for scientists to have positive motivation to constantly study on the potentials of both land and marine plants in the search of solutions and to create a healthier world. Screening a sample that is targeted to determine the proliferation or inhibition of cells would be a great start in the drug discovery field as if the result shows that the sample studied is toxic to the cell lines, therefore the sample is highly possible to penetrate the pharmaceutical industries.

Malaysia is located in South-east Asia and is well known for its rich biodiversity and would contribute to considerably huge source of primary and secondary metabolites which includes Setiu Wetlands situated on the east-coast of peninsula Malaysia facing the South China Sea and a part of the Setiu River Basin in Terengganu, Malaysia ${ }^{3}$. In Setiu, $H$ formicarum (Local name: Kepala beruk or Sarang semut) could be seen living attached on mangrove trees abundantly associated with ants sharing mutual symbiotic relationship with the species. Its tuber is affluent in chemical contents such as phenols, tannings and flavonoids ${ }^{4}$ and also reported to exhibit antimicrobial, antioxidant and anticancer properties ${ }^{5}$. This species has long been used as traditional medicine in local villages to treat many diseases including stomach ache, headache and rashes. However, most of them are not scientifically documented.

Phytochemicals in plants such as alkaloids, phenols and flavonoids have been vastly reported to have been great source of drug discovery due to their diverse pharmacological properties. Very limited studies have been done in relation to antioxidant contents and anti-cancer activities of $H$. formicarum. Previous study from Andriani ${ }^{5}$ was covered in discovering antioxidant and anti-cancer properties against cervical cancer (HeLa) and breast cancer (MCF-7) cell lines in the tuber of the respective plant in Malaysia. Another study was done on water extract of Myrmecodia pendens or also known as Ant Plant (common name) for its similar structural characteristics to $H$. formicarum as well as they both are members of the same Rubiaceae family possessed moderate anticancer potency upon treatment against cervical cancer (HeLa) and canine mammary tumor (MCM-B2) cell lines ${ }^{6}$. Study on wound healing activity of ethanol extract of $H$. formicarum tuber was also reported ${ }^{7}$. Nevertheless, most of the findings were only reported on the antibacterial, anticancer and antioxidant properties of the tuber of the plant ${ }^{5,8}$. To the best of our knowledge, there was no one study conducted on the antioxidant and cytotoxicity properties of the leaves of $H$. formicarum. Therefore, we consider the current study as a novel approach and is aimed to investigate antioxidant and cytotoxicity properties of the hexane and methanol extracts from the leaves of $H$. formicarum against HepG2 and HeLa cell lines.

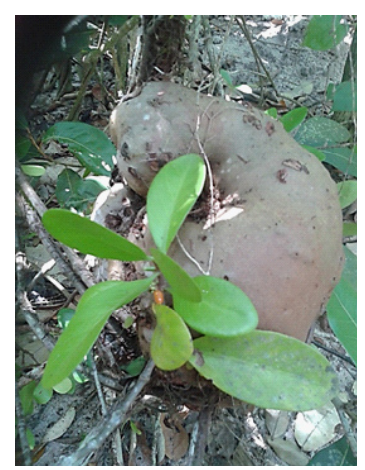

(a)

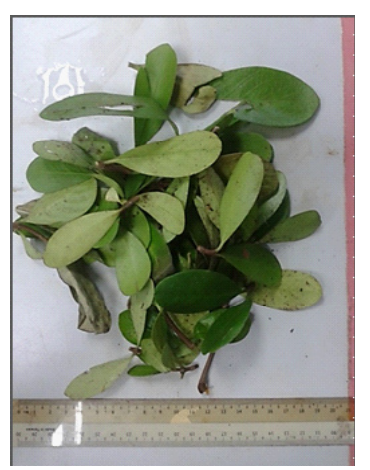

(b)
Fig. 1. Hydnophytum formicarum plant (a) and its leaves (b)

\section{MATERIALS AND METHODS}

\section{Sample Collection}

Hydnophytum formicarum leaves were collected from mangrove trees at Setiu wetland, Kuala Terengganu, Malaysia. The leaves of $\mathrm{H}$. formicarum were washed cut into small pieces, stored in freezer at $-80^{\circ} \mathrm{C}$ for $1-2$ days. Then, sample was dried by freeze-dryer for 4-5 days. The dry leaves sample were then grinded into fine powder using a grinder and the powder form leaves was stored in a sealed container in a dark, cool and dry place until further processing in the laboratory, as specified by Hasan ${ }^{9}$. The voucher specimen has been placed at Institute of Marine Biotechnology, Universiti Malaysia Terengganu (voucher numbers is TER0315003).

\section{Sample Extraction}

Powdered sample of $H$. formicarum leaves were extracted by cold maceration method using 
hexane and methanol successively as described by Andriani ${ }^{5}$. About $250 \mathrm{~g}$ leaves powder was weighed and first soaked in hexane for 3-5 days and filtered using filter paper. The filtrate was then dried using the rotary evaporator at $40^{\circ} \mathrm{C}$ to obtain hexane extract. The retained residue on the filter paper was soaked again in the hexane. The same procedure was repeated 5-6 times or until the filtrate becomes colourless. All hexane extracts yielded was combined in one bottle, weighed, and kept in refrigerator until further process. Moreover, the retained residue from the hexane extract was soaked in methanol and filtered separately. The filtrate was then dried using the rotary evaporator at $40^{\circ} \mathrm{C}$ to get methanol extract. The retained residue on the filter paper was soaked in methanol. The same procedure was repeated 5-6 times or until the filtrate becomes colourless. The extracts were combined, weighed and kept in the refrigerator for further steps.

\section{Phytochemical Screening}

Qualitative phytochemical screening of methanol extracts of $H$. formicarum leaves was done to identify the presence of flavonoids, steroids, terpenoids, saponins, alkaloids and glycosides in the study sample as described in Andriani et al., (2017) .

\section{Test for phenols and tannins}

Two millilitres of $2 \%$ ferric chloride solution is added to the methanol extract of $H$. formicarum leaves. Presence of phenol/tannins is confirmed when the mixture turns blue-green to black colour.

\section{Test for flavonoids}

The methanol extract of $H$. formicarum leaves is mixed with $2 \mathrm{~mL}$ of $2 \%$ sodium hydroxide solution. Presence of flavonoids is confirmed when a bright yellow colour was observed to turn colourless on addition of a few drops of diluted acid.

\section{Test for saponins}

The methanol extract of $H$. formicarum leaves is diluted with $5 \mathrm{~mL}$ of distilled water in a test tube and shaken vigorously. Presence of saponins is confirmed when stable foam is observed to form in the mixture.

\section{Test for glycosides}

The methanol extract of $H$. formicarum leaves is mixed with $2 \mathrm{~mL}$ of glacial acetic acid containing $1-2$ drops of $2 \%$ ferric chloride solution.
The mixture is then poured into a different test tube containing $2 \mathrm{~mL}$ of concentrated $\mathrm{H}_{2} \mathrm{SO}_{4}$ gradually and carefully. The presence of glycosides is confirmed when a brown ring interphase appears in the mixture.

\section{Test for steroids}

The methanol extract of $\mathrm{H}$. formicarum leaves is mixed with $2 \mathrm{~mL}$ of chloroform and concentrated $\mathrm{H}_{2} \mathrm{SO}_{4}$ added sidewise of a test tube. Presence of steroids is confirmed when a red colour in the lower chloroform layer is observed.

\section{Test for terpenoids}

The methanol extract of $H$. formicarum leaves is dissolved in $2 \mathrm{~mL}$ of chloroform and evaporated to dryness. Presence of terpenoids is confirmed when greyish colour forms after the addition of $2 \mathrm{~mL}$ of concentrated $\mathrm{H}_{2} \mathrm{SO}_{4}$ and heated for about 2 minutes.

\section{Test for alkaloids}

The methanol extract of $H$. formicarum leaves is mixed with $2 \mathrm{~mL}$ of $1 \% \mathrm{HCl}$ and heated gently. The Mayer's and Wagner's reagent is then added and the presence of alkaloids is confirmed when turbid precipitate forms.

\section{Thin Layer Chromatography (TLC) Profiling}

The profiling of thin layer chromatography (TLC) for the $H$. formicarum leaves extracts was done using two different types of TLC sheets. TLC plastic sheets (Merck 1.05735.0001) pre-coated with silica gel 60F254 was used for the hexane extract while TLC Aluminium sheets (Merck 1.05559.0001) pre-coated with RP-18F254S was used for methanol extract. The TLC of $H$. formicarum leave extracts were visualized with UV-365 nm, $1 \%$ ferric chloride $\left(\mathrm{FeCl}_{3}\right)$, Anisaldehyde-sulphuric acid (AS) and DPPH TLC bioautographic assay reagent spray.

\section{Determination of DPPH Free Radical Scavenging Activity}

To examine free radical scavenging activity of the $H$. formicarum leaves, DPPH free radical scavenging assay ${ }^{10}$ was used with Quercetin as the positive control and dimethyl sulfoxide (DMSO) as the negative control. Firstly, DMSO is used to dilute the sample stocks of $H$. formicarum to prepare in varying concentration by twofold serial dilution in DMSO with concentrations of $60,30,15,7.5,3.75$, $1.875,0.983$ and $0.469 \mu \mathrm{g} / \mathrm{mL}$ in 96 well plates. 
DPPH reagent was prepared with $0.04 \%(w / v)$ concentration by dissolving $2.37 \mathrm{mg}$ of the DPPH powder in $100 \mathrm{~mL}$ methanol and hexane solution. To minimize the exposure and penetration of light, the DPPH solution is shaken and immediately covered with aluminium foil. Two hundred microliter of DPPH solution $\left(6 \times 10^{-5} \mathrm{M}\right)$ was added to all wells and the mixture was covered with aluminium foil and incubates for $30 \mathrm{~min}$ at room temperature. Then, the absorbance was measured at $517 \mathrm{~nm}$ using Elisa reader.

Free radical scavenging activity were calculated using the following equation:

Free radical scavenging activity $(\%)=\frac{A_{C}-A_{S}}{A_{C}} \times 100 \%$

Where AS is the absorbance of the sample. $\mathrm{AC}$ is the absorbance of a negative control.

\section{Cancer Cell Line}

Cytotoxicity screening was carried out using HepG2 and HeLa cell lines and maintained in culture flasks. Both the cell line was kept in Minimum Essential Medium, MEM media with 10\% Fetal Bovine Serum (FBS) and 1\% Penicillin-Streptomycin at $37^{\circ} \mathrm{C}$ under $5 \% \mathrm{CO}_{2}{ }^{11}$.

\section{Laboratory Analysis}

The 3-(4,5-dimethylthiazol-2-yl)-2, 5 -diphenyltetrazolium bromide assay (MTT) was used to measure the cell proliferation under the exposure of methanol and hexane extract of $H$. formicarum, as described by Andriani ${ }^{12}$. MTT is yellow coloured and a water soluble tetrazolium salt. Succinate-dehydrogenase is a NADH-dependent cellular oxidoreductase enzymes or most commonly known as mitochondrial enzyme found in living cells that would cleave the tetrazolium ring when MTT is introduced which eventually converts yellow coloured MTT to an insoluble purple formazan. Therefore, as reported by Thavamani ${ }^{13}$, the amount of formazan produced is directly proportional to the number of viable cells. The HepG2 cell line at a density of $2 \times 10^{5}$ cells/well and HeLa cell line at a density of $4 \times 10^{4}$ cells/well was first seeded in sterile flat bottomed 96 well plastic plates. The methanol and hexane extracts were prepared in 10 different concentrations of $100,50,25,12.5,7.25,3.625$, $1.8125,0.90625,0.4531$ and $0 \mu \mathrm{g} / \mathrm{mL}, 100 \mu \mathrm{L}$ of varying concentration then added into each well and incubated for 3 days $(72 \mathrm{~h})$ at $37^{\circ} \mathrm{C}, 5 \% \mathrm{CO}_{2}$, $90 \%$ humidity.

After the incubation, $20 \mu \mathrm{L}$ is loaded to each well and incubated for 4 hours. Then, $120 \mu \mathrm{L}$ is removed from each well and $100 \mu \mathrm{L}$ of DMSO is added into each well and mixed well to completely dissolve the blue formazan crystals and the plate will be left to rest for 10 minutes. The plate will be then brought for the reading of absorbance on ELISA reader at $570 \mathrm{~nm}$ reference wavelengths. In this test, the cytotoxicity of the extract towards the cell is expressed as fifty-percent inhibition concentration $\left(\mathrm{IC}_{50}\right) \cdot \mathrm{IC}_{50}$ value is the concentration of compound required to inhibit $50 \%$ cell growth. Interpolations of both $X$ and $Y$ axis is made by drawing a line from the $50 \%$ value. The antilog of that value gives the $\mathrm{IC}_{50}$ value. Sample which exhibit cytotoxic index $\mathrm{IC}_{50}<30$ $\mu \mathrm{g} / \mathrm{mL}$, is considered to have significant cytotoxic activity ${ }^{14}$. After the sample analysis, a graph of cell viability against concentration is plotted showing the cytotoxicity properties of methanol and hexane extract of $H$. formicarum leaves in HepG2 and HeLa cell line after 72 hours.

Percentage inhibitions of the extract against all cell lines were calculated using the following formula:

$\%$ cell survival $=\frac{(A t-A b)}{(A c-A b)} \times 100$

Where, At $=$ Absorbance of Test

$\mathrm{Ab}=$ Absorbance of Blank (Cell + media)

$\mathrm{Ac}=$ Absorbance of control (cells) $\%$ cell inhibition = $100-\%$ cell survival

\section{Data analysis}

All the experiments were conducted in triplicate and presented as mean values \pm standard deviation.

\section{RESULTS}

Phytochemical screening was carried out on H. formicarum leaves methanol extract to detect the presence of phenols/tannins, flavonoids, saponins, glycosides, steroids, terpenoids and alkaloids (Table 1). The screening indicated the presence of four phytochemical compounds in the H. formicarum leaves methanol extract including phenols/tannins, flavonoids, glycosides and steroids. 
Table 1: Phytochemical screening for the methanol extract of $\boldsymbol{H}$. formicarum leaves

\begin{tabular}{lc}
\hline Phytochemical & Result \\
\hline Phenols/tannins & + \\
Flavonoids & + \\
Saponins & - \\
Glycosides & + \\
Steroids & + \\
Terpenoids & - \\
Alkaloids & - \\
\hline$+=$ presence; $-=$ absent
\end{tabular}

A series of solvent was used, ranging from lowest to highest polarity in the Thin Layer Chromatography (TLC) profiling of $H$. formicarum leaves extracts. The profiles were visualized with several indicative measures including Ultraviolet visible light with $\lambda=365 \mathrm{~nm}$ and reagent sprays of anisaldehyde-sulphuric acid (AS), ferric chloride and DPPH. Based on Fig. 2, the most suitable composition of solvents for hexane leaves extract and methanol leaves extracts were a mixture of hexane:ethyl acetate $=7: 3$ and chloroform:methanol $=3: 7$, respectively. Mostly, bands observed under the UV light signified the presence of aromatics and fluorescence compounds. Whereas, bright yellowish colour with a wide spot area on purple background in the TLC after sprayed by DPPH reagent showed that the most significant compound detected was phenolic compounds. It's indicating the presence of compounds that could contributes to antioxidant activity. The intensity of the bright yellow coloured bands showed a difference in the level of scavenging. However, the intensity of the bright yellow bands displayed by the methanol extract TLC profiling was higher than that of hexane extract which indicates that antioxidant or free radical scavenging activity is higher in methanol compared to hexane extract. In addition, the TLC profiling that was sprayed with $1 \%$ $\mathrm{FeCl}_{3}$ showed brown spots indicating the existence of phenolics compound. This was also proven by the appearance of violet, blue and red spots after being sprayed with Anisaldehyde sulphuric acid reagent (AS) and heated with a dryer to maximize visualization of spots indicated the presence of phenols, terpenes, sugars, and steroids ${ }^{15,16}$.

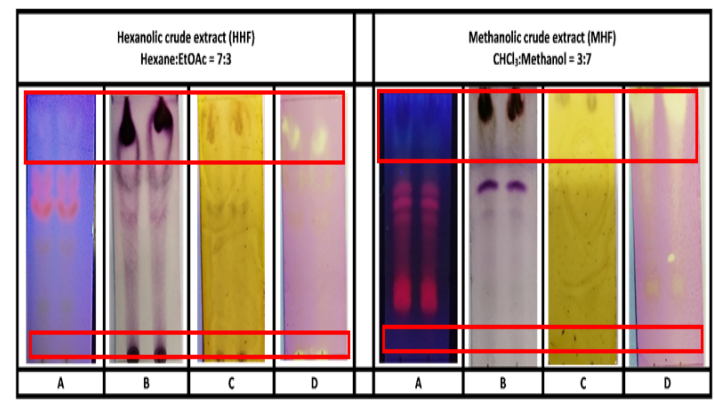

Fig. 2. TLC profiling of $H$. formicarum leave extracts after visualization with UV-365 nm (a), Anisaldehyde (b), $\mathrm{FeCl}_{3}$ reagent spray (c), DPPH (d)

The DPPH (2, 2-diphenyl-1-picrylhydrazyl) free radical scavenging assay is commonly used to evaluate the antioxidant potential. The DPPH free-radical scavenging potential of leaves extracts of $\mathrm{H}$. formicarum is shown in Fig. 3. Generally, both the methanol and hexane extracts of $H$. formicarum leaves showed high scavenging ability towards the DPPH free radicals indicating good antioxidant potential. However, methanol extract showed the highest and the most significant scavenging percentage of DPPH free radicals compared to hexane extract. Thus, methanol extract has the highest antioxidant potential which shows the lowest $I_{50}$ value of $0.4 \mathrm{mg} / \mathrm{mL}$, quite similar to the quercetin $\left(\mathrm{IC}_{50}=0.3 \mathrm{mg} / \mathrm{mL}\right)$. The $\mathrm{IC}_{50}$ value of each sample was measured by plot the concentration of each sample which crosses with its $50 \%$ of antioxidant activity Figure 3 .

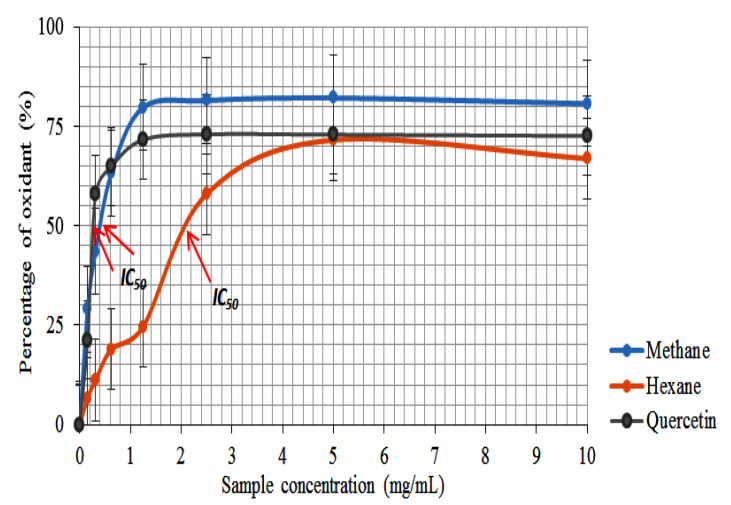

Fig. 3. DPPH free radical scavenging property of H. formicarum leaves as compared to the Quercetin

The cytotoxic activity of two different extracts of the epiphyte collected from coastal mangrove ecosystem namely $H$. formicarum against HeLa and HepG2 cell lines were incubated with different doses ( 0 to $100 \mu \mathrm{g} / \mathrm{mL}$ ) of extracts. The viability of the cell lines was determined using MTT 
assay after $72 \mathrm{~h}$ of incubation. The results of cytotoxic assay are as presented in Fig. 4. Some of the extracts induced cell cytotoxicity in a concentration dependant manner as illustrated. The cytotoxicity of the extract towards the cell is expressed as fifty-percent inhibition concentration $\left(\mathrm{IC}_{50}\right)$ as per the guidelines for cytotoxicity activity for extracts by The American National Cancer Institute $(\mathrm{NCl})$ by which the extract that exhibits cytotoxic index $\mathrm{IC}_{50}<30 \mu \mathrm{g} / \mathrm{mL}$ after exposure time of $72 \mathrm{~h}$ will be considered to have significant cytotoxic activity ${ }^{17}$. Based on the cytotoxicity results in Fig. 4, the lowest $\mathrm{IC}_{50}$ value below this point was only noted with methanol extract in cervical cancer cell lines of $22 \mu \mathrm{g} / \mathrm{mL}$. Meanwhile, hexane extract in cervical cancer cell lines and methanol extract in liver cancer cell lines showed $48 \mu \mathrm{g} / \mathrm{mL}$ and $65 \mu \mathrm{g} / \mathrm{mL}$ respectively indicating both has relatively lower cancer cell proliferation inhibiting properties. While, hexane extract in liver cancer cell line portrayed no cytotoxic activity at all.

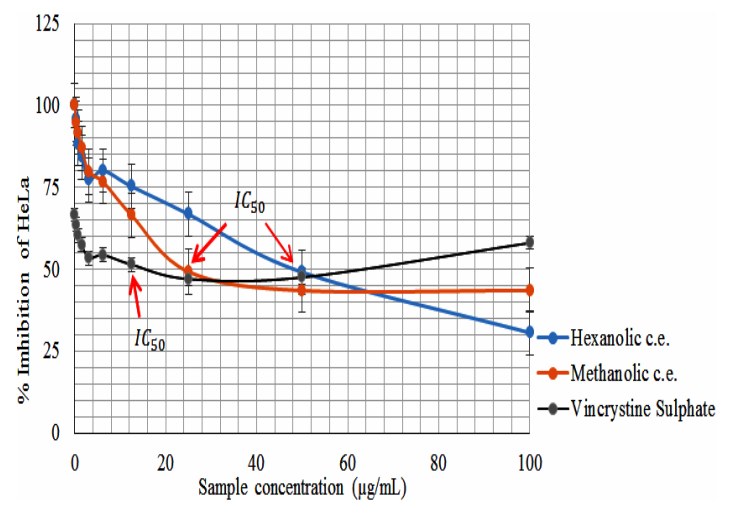

(a)

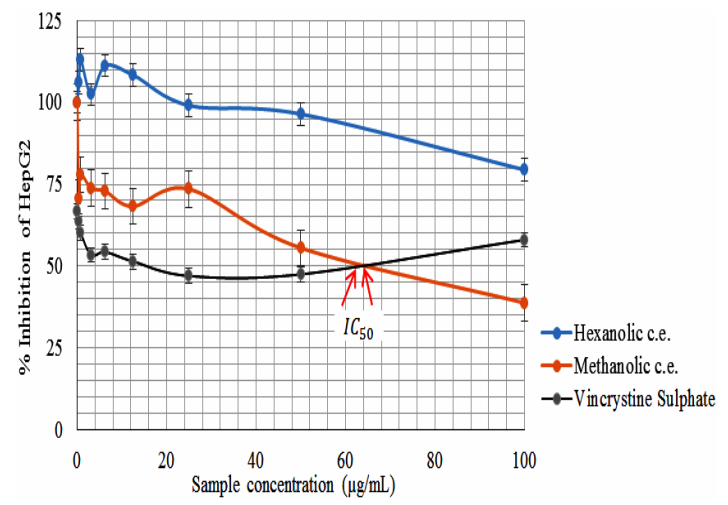

(b)

Fig. 4. Cytotoxicity activity of methanol and hexane extract of $\boldsymbol{H}$. formicarum leaves as compared to Vincristine Sulphate against HeLa (a) and HepG2 (b) cell lines

\section{DISCUSSION}

The phytochemical result indicated positive for phenolic compounds including phenols, tannins and flavonoids, glycosides and steroids content in leaves of $\mathrm{H}$. formicarum. These compounds are known to exhibit both pharmacological and physiological properties ${ }^{18}$. Phenols and tannins were identified by the appearance of blue-green to black colour upon the mixture of the leaves extract and ferric chloride solution and was then confirmed using the TLC by the presence of brownish spots appearing as the TLC sheet was sprayed with ferric chloride reagent. Meanwhile, presence of flavonoids was confirmed when bright yellow colour mixture of the leaves extract and sodium hydroxide turns colourless as acid is added gradually. The same phytochemicals content exists in tuber of $H$. formicarum collected from the same area (Setiu wetland, Kuala Terengganu, Malaysia), except flavonoids ${ }^{5}$.

Phenolic compounds are the largest class of phytochemicals that is responsible for most of the medicinal activities in natural products. They are also known to have a wide range of biochemical activities that includes antioxidant ${ }^{19}$, anti-tumor ${ }^{20}$ and anti-carcinogenic ${ }^{21}$ as well as able to alter the expression of genes ${ }^{22}$. Phenolic compounds are considered to be a powerful antioxidant and are proven to be more potent than Vitamin $C$ and $E$ and carotenoids $^{23}$. They are able to reduce the risk of cancer by protecting biological systems in the human body due to their high potentials of scavenging free radicals that induces oxidative stress ${ }^{24}$. It is due to the imbalance of production of reactive oxygen species (free radicals) and antioxidant defences ${ }^{25}$. Meanwhile, the presence of steroids and glycosides in $H$. formicarum leaves extracts were detected by the presence of brown ring interphase and the appearance of red colour in the lower chloroform layer in the mixture of the leaves extract and the test reagents, respectively.

Free radicals are produced because of incomplete reduction of oxygen molecule ${ }^{26}$. The increase of free radicals often accumulates with age and is usually derived from normal metabolic processes or environmental factors including exposure to air pollutants, radioactive and chemical sources ${ }^{27}$ due to enzymatic and non-enzymatic reactions in human ${ }^{28}$. Many documented that they cause harmful effects including hypertension, 
asthma, diabetes, cardiovascular conditions, cancer inflammatory diseases, neurological disorder, early ageing and many others ${ }^{29,30}$.

Compounds that contribute to antioxidant activity in the leaves extract of $H$. formicarum was also evident on the TLC sheet when sprayed with DPPH reagent visualized as bright yellow colour bands on purple background by which the intensity of the colour depicted the antioxidant capacity ${ }^{31}$. It was further verified using the DPPH (2,2-diphenyl-1picryl-hydrazyl-hydrate) free radical scavenging assay carried out on the methanol and hexane extracts of $H$. formicarum leaves. The result of the test is presented in Fig. 3. DPPH assay is the most common, rapid and inexpensive method to evaluate the antioxidant activity ${ }^{32}$. This assay works based on the reduction of the stable free radical, DPPH that gives a maximum absorption at $517 \mathrm{~nm}$. It is analysed by the level of absorbance whereby purple coloured DPPH turns to pale yellow colour as it mixes with a substance that is able to donate Hydrogen atom ${ }^{33}$.

In the current study, 3-(4) 5-Dimethylthiazol-Zyl) - 2,5 biphenyl tetrazolium bromide (MTT) assay was used to investigate the cytotoxic property of $H$. formicarum leaves methanol and hexane extracts against HeLa and HepG2 cell lines. The results showed that the viability and growth of cells were inhibited in a dose dependent manner. The methanol extracts of $H$. formicarum against HeLa cell line were found to be more potent as it exhibited stronger cytotoxic activities compared to hexane extracts, as evident by the low concentration $(22 \mu \mathrm{g} / \mathrm{mL}$ ) where $50 \%$ of cell growth inhibition occurred. The $\mathrm{IC}_{50}$ value of methanol extract was found to be more efficient on cervical cancer cells. Nevertheless, both the methanol and hexane extracts of $H$. formicarum leaves showed relatively low cytotoxic activity (IC50>30 $\mu \mathrm{g} / \mathrm{mL})$ against HepG2 cell line with IC50 values of $50 \mu \mathrm{g} / \mathrm{mL}$ and $60 \mu \mathrm{g} /$ $\mathrm{mL}$, respectively. Based on previous studies, many suggested that bioactive compounds in natural products plays a dominant role in exerting cytotoxic properties and are potential source of potent natural anti-cancer agents ${ }^{34,35,36,37}$.

The presence of potent phytochemical compounds like phenol/tannins, flavonoids, glycosides and steroids in this study could probably be responsible for the anticancer activity of
$H$. formicarum leaves as they are in agreement with many studies reporting these compounds have the potential to be therapeutic against cancer ${ }^{6,38,39,40}$. However, more research is needed for a better understanding of the association between these phytochemicals and anticancer activity in $H$. formicarum leaves extracts. Previous studies on $H$. formicarum found in Malaysia has showed supportive evidences to the current study, however they were focused on different sampling areas and parts of the plant $t^{5,41,42}$. Thus, the current study on the antioxidant and cytotoxic properties of Malaysian $\mathrm{H}$. formicarum leaves against HeLa and HepG2 cell lines are firstly described. According to Vaibhav ${ }^{43}$, difference in environmental conditions, collection and preparation procedures may rise considerable variability in the bioactive compounds that are present in the plant. Evidences on the medicinal properties of Malaysian H. formicarum are scarce and more data is necessary and would be very useful for future studies. The current study shows promising evidences for the sample to be potential antioxidant and anti-cancer agents provided with further research on the individual bioactive compounds and testing with more type of cancer cells in respect to normal cells.

\section{CONCLUSION}

The findings indicated that $H$. formicarum leaves possesses very good antioxidant and cytotoxic properties and is promising for its further development as antioxidant and anticancer potential agents especially for cervical cancer treatment. Phytochemicals analysis in the current study showed the presence of phenols/tannins, flavonoids, glycosides, and steroids. Hypothetically, phenolic compounds that were most abundantly found in the analysis could have been the main contributor to its antioxidant and anticancer potencies. Thus, the findings of this study suggests further research is required, especially to separate and purify the bioactive compounds in the leaves extract as to ascertain the compound that is responsible for the antioxidant and cytotoxicity activity as well as to also test the potency of the extract against different types of cancer cell lines.

\section{ACKNOWLEDGEMENT}

We wish to thank the Institute of Marine Biotechnology, UMT, Kuala Nerus, Malaysia, for the research and laboratory facilities.

\section{Conflicts of interest}

No conflict of interest. 


\section{REFERENCE}

1. World Health Organization Cancer. Retrieved from who.int/news-room/fact-sheets/detail/ cancer., 2018.

2. Khan, H. J. Evid. Based Complementary Altern. Med., 2014, 19(3), 216-219.

3. WWF, Sustainable Management of Setiu Wetland. Retrieved from http://www.wwf.org. my., 2008.

4. Darwis, D.; Hertiani, T. and Sasmito, E. Journal of Applied Pharmaceutical Science., 2014, 4(6), 103-109.

5. Andriani, Y.; Mohamad, H.; Kassim, M.; Rosnan, N.; Syamsumir, D.; Saidin, J.; Muhammad, T. and Amir, H. Journal of Applied Pharmaceutical Science., 2017, 7(09), 030-037.

6. Soeksmanto A.; Subroto, M. A.; Wijaya, H. and Simanjuntak. P. Pakistan J Biol Sci., 2010, 13, 148-151.

7. Putri, S. A.; Ismardianita, E. Padjajaran Journal of Desitry., 2016, 28(3), 177-182.

8. Prachayasittikul, S. \& Buraparuangsang, P. \& Worachartcheewan, A. \& IsarankuraNa-Ayudhya, Chartchalerm \& Ruchirawat, S. \& Prachayasittikul, V. Molecules., 2008, 18;13(4), 904-21.

9. Hasan, M.; Hossain, A.; Shamim, A. and Rahman, M. BMC Complement Altern Med., 2017, 17, 496.

10. Kumaran, A. and Karunakaran, R. Food Chemistry., 2006, 97, 109-114.

11. Wahyu, W.; Laura, W.; Teresa, L. W.; Indra, B.; Yellianty, Y. \& Dian, R. L. J. Exp. Integr. Med., 2013, 3, 225-230.

12. Andriani, Y. \& Wahid, Effendy \& Sifzizul, T. \& Mohamad, H. International Journal of Pharmaceutical Sciences and Research., 2011, 2, 1700-1706.

13. Thavamani, B. S., Mathew, M., and Dhanabal, S. P. Ancient science of life., 2013, 33(2), 81-84

14. Saetung, A.; Itharat, A.; Dechsukum, C.; Wattanapiromsakul, C.; Keawpradub, N. and Ratnasuwan, P. Journal of Science and Technology., 2005, 27, 469-478.

15. Mangold, H.; Schmid, H. and Stahl, E. In book: Methods of Biochemical Analysis., 2006, 12, 393-451.
16. Laboratory of Catalysis and Organic Synthesis TLCVisualisation Reagents. École polytechnique fédérale de Lausanne (EPFL). Retrieved from https://www.epfl.ch/labs/lcso/wp-content/ uploads/2018/06/TLC_Stains.pdf., 2018.

17. Abdel-Hameed, E. S.; Salih, A.; Bazaid, S. A.; Shohayeb, M. M.; El-Sayed, M. M. and El-Wakil, E. A. Eur J Med Plants., 2012, 2, 93-112.

18. Shrestha, P., Adhikari, S., Lamichhane, B. and Shrestha, B. IOSR Journal of Environmental Science, Toxicology and Food Technology., 2015, 1, 2319-2399.

19. Mohammad Reza, S. A., Mahnaz, K., Mannan, H., Maryam J. and Abbas H. Iranian Journal of Pharmaceutical Research., 2010, 9(2), 141-146.

20. Basli, A., Belkacem, N., and Amrani, I. Health Benefits of Phenolic Compounds Against Cancers, Phenolic Compounds Biological Activity, Marcos Soto-Hernandez, Mariana Palma-Tenango and Maria del Rosario Garcia-Mateos, IntechOpen, DOI: 10.5772/67232. Retrieved from https://www. intechopen.com/books/phenolic-compoundsbiological-activity/health-benefits-of-phenoliccompounds-against-cancers., 2017.

21. Zhang, Y., Seeram, N. P., Lee, R., Feng, L. and Heber, D. Journal of Agricultural of Food Chemistry., 2008, 56, 670-675.

22. Marinova, D., Ribarova F. and Atanassova M. Journal of Chemical Technology and Biotechnology., 2005, 40(3), 255-260.

23. Lee, K. W. and Lee, H. J. Biofactors., 2006, 26(2), 105-121.

24. Pham-Huy, L. A., He, H., \& Pham-Huy, C. International journal of biomedical science, IJBS., 2008, 4(2), 89-96.

25. Akar, Z.; Kucuk, M. and Dogan, H. Journal of Enzyme Inhibition and Medicinal Chemistry., 2017, 32, 640-647.

26. Krumova, K. \& Cosa, G. In book: Comprehensive Series in Photochemical \& Photobiological Sciences., 2016, 1,1-21.

27. Aseervatham, G. S. B., Sivasudha, T., Jeyadevi, R., \& Arul Ananth, D. Environmental Science and Pollution Research., 2013, 20(7). 
28. Lobo, V.; Patil, A.; Phatak, A., and Chandra, N. Pharmacognosy reviews., 2010, 4(8), 118-126.

29. Maddu, N. Diseases Related to Types of Free Radicals, Antioxidants, Emad Shalaby, IntechOpen, DOI: 10.5772/intechopen.82879. Retrieved from https://www.intechopen.com/ books/antioxidants/diseases-related-totypes-of-free-radicals., 2019.

30. Valko, M.; Leibfritz, D.; Moncol, J.; Cronin, M.; T., Mazur, M. and Telser, J. Int J Biochem Cell B., 2007, 39, 44-84.

31. Wang, J.;Yue, Y.; Tang, F. and Sun, J. Molecules., 2012, 17, 12297-12311.

32. Kirtikar, K. R. and Basu, B. D. International book distributors, Dehradun., 2006, 993-994.

33. Hangun-Balkir, Y. \& McKenney, M. L. Green Chemistry Letters and Reviews., 2012, 5(2), 147-153.

34. Subramaniam, S.; Selvaduray, K. R., and Radhakrishnan, Biomolecules., 2019, 9(12), 758.

35. Iqbal, J.; Abbasi, B. A.; Mahmood, T.; Kanwal, S.; Ali, B.; Shah, S. A.; and Khalil, A. T. Asian Pacific Journal of Tropical Biomedicine., 2017, 7(12), 1129-1150.

36. Greenwell, M., and Rahman, P.K. International journal of pharmaceutical sciences and research., 2015, 6(10), 4103-4112.

37. Patel, R.; Patel, Y.; Kunjadia, P. and Kunjadia, A. International Journal of Current Microbiology and Applied Sciences., 2015, 4(1), 773-780.

38. Salinas-Santander, M.; Alvarez-Ortiz, P.; Alberto-Ascacio Valdes, J.; Rodriguez-Herrera, R.; Zugasti-Cruz, A.; Rangel-Zertuche, R., Valencia, V. J. S. and Morlett-Chavez, A. Pharmacognosy - Medicinal Plants. Shagufta Perveen \& Areej Al-Taweel, IntechOpen. 2019, DOI: 10.5772/intechopen.82258.

39. Mushtaq, S.; Abbasi, B. H.; Uzair, B.; and Abbasi, R. EXCLI Journal., 2018, 17, 420-451.

40. Ghasemzadeh, A.; Jaafar, H.Z.E.; Rahmat, A.\& Devarajan, T. Evidence-Based Complementary and Alternative Medicine, 2014, 1-8.

41. Shahrudin, R.;Yusoff, A.S.; Kamaruzzaman, M.F. \& Salam, M. R. Journal of Sustainability Science and Management., 2017, 12(2), 128-134.

42. Abdullah, N. S.; Ahmad, W.Y.W. and Sabri, N. A. Malaysian Journal of Analytical Sciences., 2017, 21(4), $778-783$.

43. Vaibhav, M.S.D. Kamlesh, P. Manohar, \& Kakasaheb, R. M. International Journal of Phytomedicine., 2009, 1, 4-8. 